Final Report

U.S. Department of Energy

\title{
New Permeameters for in situ Characterization of Unsaturated Heterogeneous Permeabillty: Development, Design, Testing, and Application
}

\author{
John L. Wilson, Lead Principal Investigator \\ New Mcxico Institute of Mining and Technology \\ Department of Earth and Environmental Science \\ Socorro, NM 87801 \\ 505-835-5308 \\ jwilson@nmt.edu
}

and

Robert J. Glass, Co-Principal Investigator

Sandia National Laboratories

Division 6115

P.O. Box 5800, MS 1345

Albuquerque, NM 87185-1345

505-844-5606

rjglass@nwer.sandia.gov

December 1, 2001

Project Number: 55109

Grant Number: DE-FG07-96ER14704

Grant Project Officer: Nick Woodward

Project Duration: 7/15/1996- 7/15/2000 


\section{TABLE OF CONTENTS}

Page

Executive Summary

Research Objectives $\quad 4$

Methods and Results 5

Relevance, Impact and Tcchnology Transfer 11

$\begin{array}{ll}\text { Publications } & 13\end{array}$

$\begin{array}{ll}\text { Intcractions } & 14\end{array}$

$\begin{array}{ll}\text { Transitions } & 15\end{array}$

$\begin{array}{ll}\text { Patents } & 15\end{array}$

$\begin{array}{ll}\text { Future Work } & 15\end{array}$

$\begin{array}{ll}\text { References } & 17\end{array}$ 


\section{EXECUTIVE SUMMARY}

The original objective of our EMSP research was to design, develop, and test new in situ ficld permeameters for use in spatial variability studies of unsaturated hydraulic properties. We initially focused on activities related to development and testing of techniques for inverting permeameter data, development of numerical tools for data inversion, error evaluation for permeameter design, and permeameter component design. However, the results of error evaluations for permeameter design caused us to redirect our research, and reformulate our research objectives. We discovered that small, simple measurement errors lead to significant bias in the estimated hydraulic properties and their spatial statistics. Our reformulated research objective became the cvaluation of the origin, impact and relevance of spatial bias in field- and laboratory-estimated unsaturated hydraulic propertics, with an emphasis on spatial statistics and the resulting predictions of stochastic models of flow and contaminant transport.

Spatial statistics of hydraulic properties can be accurately estimated when measurement errors arc unbiased. Unfortunately, measurements become spatially biased (i.e., their spatial pattern is systematically distorted) when random observation errors are propagated through nonlinear inversion models or inversion models that incorrectly describe experimental physics. This type of bias results in a distortion of the spatial distribution and statistics of the hydraulic property and in crroneous predictions of flow and transport.

We developed a Monte Carlo approach to determine the spatial bias in field- and laboratory-estimated unsaturated hydraulic properties subject to simple measurcment errors. For these analyses, we simulated measurements in a series of idealized realities and considered only simple measurement errors that can be easily modclcd. We found that hydraulic properties are strongly biased by small observation and inversion-model errors. This bias leads to order-ofmagnitude crrors in spatial statistics and artificial cross-correlation between measured properties. We also found that measurement crrors amplify uncertainty in estimated (experimental) variograms and can preclude identification of variogram-model parameters. Using biased spatial statistics in stochastic flow and transport models yields order-of-magnitude errors in critical transport predictions. The effects of observation and inversion-model crrors are insidious, as hydraulic property estimates may appear reasonable and generate realistic looking spatial statistics that are, however, inaccurate and misleading. 


\section{RESEARCH OBJECTIVES}

Thick unsaturated zones underlie many Department of Encrgy (DOE) landfills, industrial areas, and wastc storage sites in the westem United Statcs and are the primary pathway for contaminants to migrate into underlying aquifcrs. The spatial variability of unsaturated hydraulic properties in these heterogeneous geologic materials directly influences the movement of water and non-aqueous phase liquids (NAPL's). Poor characterization of heterogeneity also lcads to ineffective remedial designs and increased risk, requiring subsequent additional remedial actions at increased cost and time. Remcdial design can be improved using probabilistic riskbased decision analysis, which can require a large number of hydraulic property observations to characterize the spatial statistics of the heterogeneous properties. One of the most important propertics is unsaturated permeability. Laboratory methods for estimating unsaturated permeability are expensive, time-consuming, and may not yield results representative of heterogeneous field conditions. Simple and rapid field methods for estimating in situ unsaturated permeability are appealing and potentially cost-effective.

The original objective of this EMSP research was to design, develop, and test new field permeameters for usc in spatial variability studies. We cstablished a series of permeameter design criteria, including: 1) measurements should be relatively rapid, 2) the total cost per data point should be low, 3) results would accurately reflect the variation of unsaturated hydraulic properties between sampled locations, 4) the volume sampled (measurement support) would be small, and 5) useful range would be relevant to the range of soil moisture conditions encountered at DOE sites. We initially focused on activities related to development and testing of techniques for inverting permeameter data, development of numerical tools for data inversion, error evaluation for permeameter design, and permcameter component design. However, the results of error evaluations for various alternative permeameter designs caused us to redirect our research, and reformulate our research objectives (sce, cg, Wilson, 1998). We discovered that small, simple measurement errors lead to significant bias in estimated hydraulic properties and their spatial statistics.

Our reformulated research objective became the evaluation of the origin, impact and relevance of bias in field- and laboratory-estimated unsaturated hydraulic propertics, including its effects on estimated spatial statistics and the predictive modeling of contaminant migration. We focused on three fundamental questions:

1) Do simple observation and inversion-model errors cause bias in spatial statistics; if so, how does this bias originatc and what is its magnitude?

2) Can we characterize the spatial statistics of unsaturatcd hydraulic properties in the presence of measurement errors?

3) Are probabilistic models of flow and transport sensitive to spatial bias caused by measurement error?

To address these questions, we developed a new Monte Carlo approach for examining the spatial bias in estimates of hydraulic properties subject to simple observation and inversion-model errors. 


\section{METHODS AND RESULTS}

Our research shows, for thc first time, that bias in property measurements adversely affects our ability to characterize spatial variability and model flow and transport in heterogencous systems. Measured hydraulic properties become biased when random observation errors are propagated through non-linear inversion models that may also incorrectly describe experimental physics. In engincering and physics, measurement bias can be experimentally evaluated and removed through the use of calibration standards. The entire instrument, including the inversion model, must be calibrated to overcome the inversion non-linearity. This is often infeasible in hydrology because physical standards do not exist and inversion-model errors vary unpredictably between individual samples. In hydrologic spatial variability studies, it is also impossible to fully calibrate estimates of the spatial statistics. Therefore, the effect of bias on spatial statistics cannot be directly quantified, and instead must be examined indirectly.

Hydraulic properties (e.g., permeability) are estimated using an observed systcm response to a perturbation (c.g., pumping). The observations are inverted through a mathematical model of the experiment. Errors in estimates of hydraulic properties (property-estimation crrors) arise from both measurement and inversion-model errors. Measurement crrors result from exroneous, dircct observation of system or device states (e.g. pressure, flow rate, and the location of observation points) and are non-linearly propagated through the inverse solution for the hydraulic property. Because mcasurement errors are a function the hydraulic response of the sampled system and the "true" valuc of the hydraulic property, estimation errors are often correlated with the true hydraulic-property. Inversion model error results when the fundamental assumptions of the inversion model are invalid. This type of error can result from an incorrect mathematical model, an inappropriate parametric model, sub-sample-scale heterogencity, scaling-effects, boundary condition errors, and other unresolved or ill-described physics in the system or the instrument. Most inversion-model crrors introduce systematic errors in the estimated hydraulic property and can be correlated with the true values of the sampled field.

We developed a new Monte Carlo approach to indirectly determine spatial bias in estimates of hydraulic properties subject to simple observation and inversion-model errors and to quantify its potential effect on stochastic model results. Our approach is straightforward (Figure 1). Using standard stochastic methods (e.g., Robin et al., 1993), we synthetically gencrate and sample a series of artificjal spatial realities (sets of parameter fields). At each sampled location, observation and inversion-model crrors are propagated through numerical sinulations of parameter measurcments. Using this approach we can make hundreds of thousands of virtual measurements. The spatial structure of the resulting parameter estimatcs is compared to the spatial structure of the underlying reality, revealing the extent of spatial bias. To evaluatc the sensitivity of bias to the true field statistics, this procedurc is repeated across parameter spaces (varying the mean value of properties) selected to represent a range of realistic materials (from fine to coarse, from well sorted to poorly sorted).

To estimate properties with this approach three different models are uscd. First we model the instrument and system to determine the system rcsponse to a perturbation. Second we model

$$
-5 .
$$


the errors affecting observations of the perturbation and the state variables. Third we model the measurement-specific inversion for estimating parameters. When invcrsion-models are simple and require only steady-state data (c.g., the tension infiltrometer), the system response is

modeled using analytical models. Otherwise, numerical methods are used to simulate the system response.

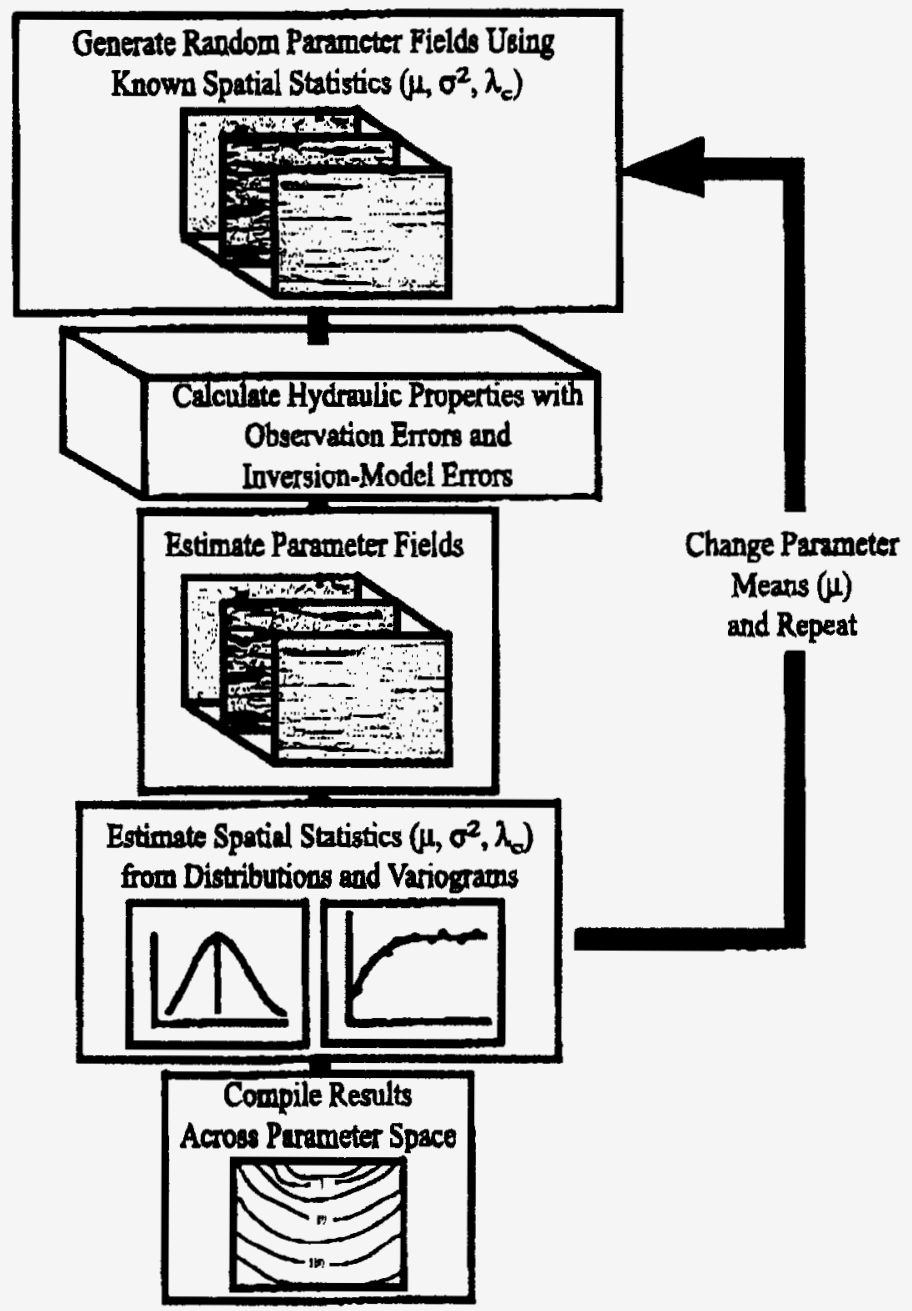

Figurc 1. Schematic of the Monte Carlo process used to evaluate bias in spatial statistics. From Holt et al., 2002a.

Inversion-model errors are incorporated within the system-response model, whilc observation errors are added to observations of the perturbation and state variables prior to use in inversion models for estimating parameters. Observation-error models are constructed using data collected for instruments in our laboratories at the New Mexico Institute of Mining and Technology and at Sandia National Laboratories. For conventional instruments inversion models for cstimating parametcrs follow published and accepted methods. Models for inversionmodel errors are developed based on our experiences in the laboratory and field. 


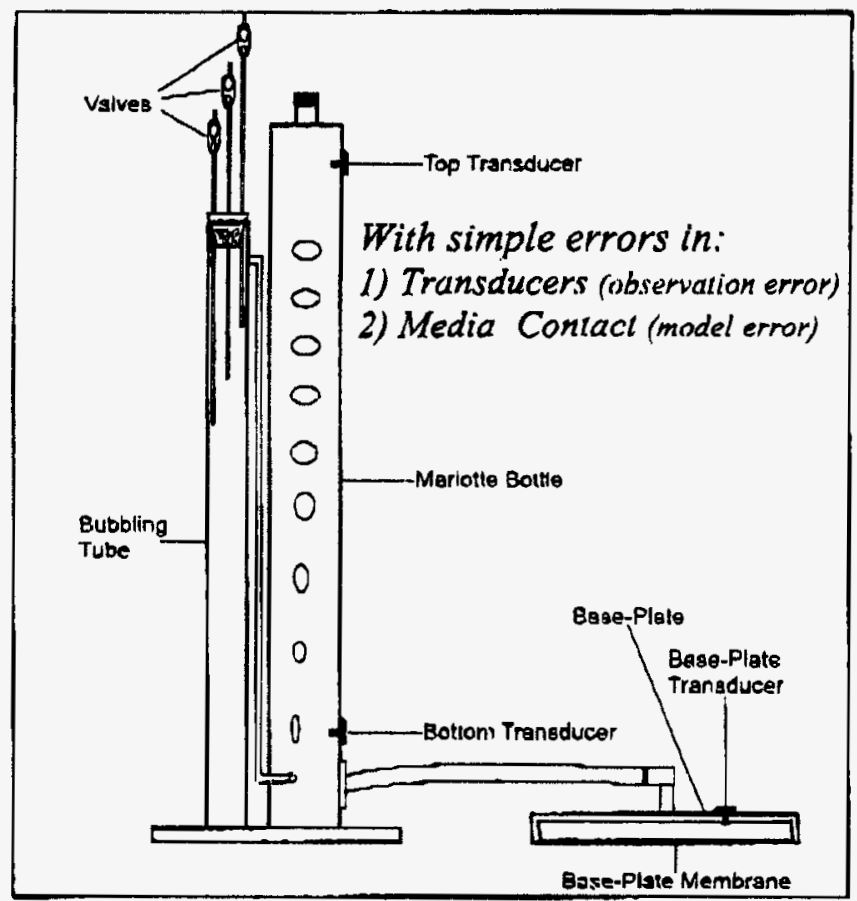

Figure 2. Significant bias for the tension infiltromenter occurred when only the noise in the transducers was accounted for. Larger bias resulted by adding only one model error, represented by incomplete contact (never less than $90 \%$ ) of the base plate with the underlying porous media. From Holt et al, $2002 a$.

In Holt (2000) and Holt et al. (2002a) wc evaluate measurement-error-induced bias in the spatial statistics of tension infiltrometer measurcments. The tension infiltrometer is a common field instrument for making in situ measurements (Figure 2), and is used to estimate the saturated hydraulic conductivity and an exponential relative permeability parameter. In our study we include only small simple obscrvation errors of infiltrometer flux and the applied tension at the disk source, and a boundary condition or inversion model error concerning disk contact with the soil surface (Figure 2). Because we find that the tension infiltrometer performs so poorly (see below) for estimating the spatial statistics of in situ unsaturated hydraulic properties, we also evaluate laboratory methods for estimating unsaturatcd hydraulic properties and their impact on estimates of spatial statistics. In principle, laboratory methods provide the most accurate estimates of unsaturated hydraulic properties, becausc inversion models are simple and subject to fewer sources of error. In Holt (2000) and Holt et al. (2002c, in review) we consider laboratory estimates of the saturated hydraulic, porosity, and the van Genuchten (1980) unsaturated hydraulic parameters ( $\alpha$ and $n$ ). We simulate laboratory measurements in the presence of simple observation errors and inversion model errors, including equilibrium errors, heterogeneity at the base of the sample, and sample repacking. Because most applied spatial variability studies rely on a limited number of samples, we also examined the uncertainty in spatial statistics as a function of the number of samples. In Holt (2000) and Holt et al. (2002b, accepted) we detcrmine the impact of measurement errors on predictions made with $1 \mathrm{D}$ and $3 \mathrm{D}$ unconditional 
unsaturated stochastic models of unsaturated flow and transport. The major conclusions of this research are presented below.

We found that small errors in observations and simple inversion-model errors can cause significant spatial bias in hydraulic property estimates when hydraulic properties are estimated with a non-linear inversion model. Bias results when observation crrors are propagated through the inversion model or from errors in the inversion model itself. The extent of bias depends on the degree of non-linearity in the inversion model, the true values of the sampled hydraulic properties, and the nature of the observation and inversion-model errors. Bias is manifested as a systematic distortion that also affects quantitative measures of spatial variability including the mean, variance, variogram, and the variogram model parameters, and can lead to order-ofmagnitude errors in these statistics (sce Figure 3; Holt, 2000; Holt et al., 2002a,c). Artificial cross-corrclation between estimated parameters results when multiple parameters are estimated from a singlc non-linear inversion model (Holt, 2000; Holt et al., 2002a,c). Measurement etrors
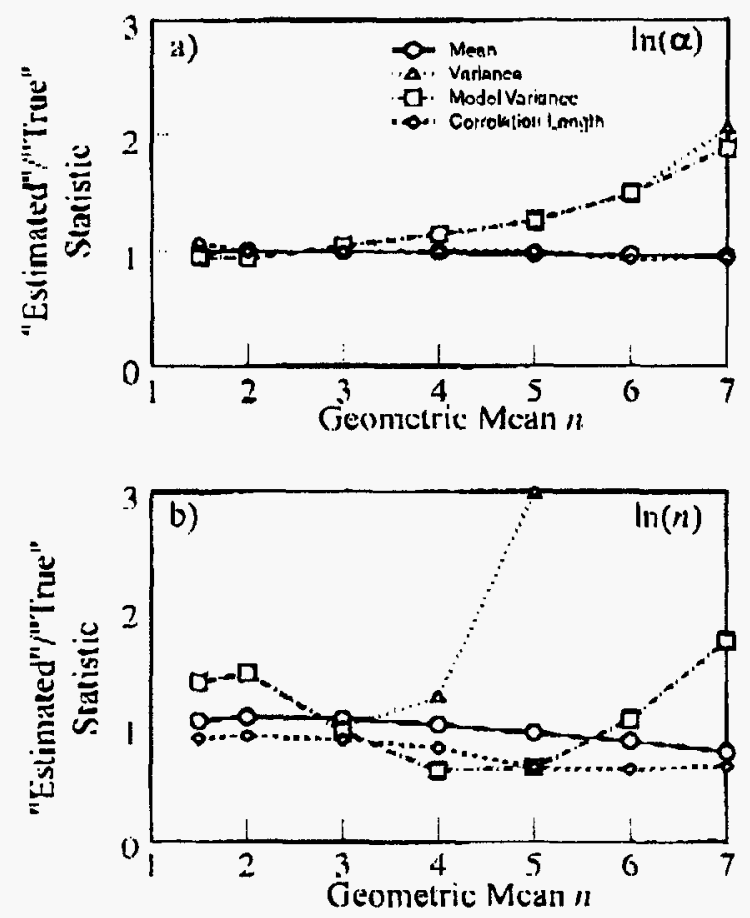

Figure 3. Bias in spatial statistics of the log of two van Genuchten parameters, a) $\ln (\hat{\alpha})$ and b) $\ln (\hat{n})$, for laboratory measurements of moisture retention with both observation and model errors. The horizontal axes reprcsents different type of materials, each one with a spatially distributed field of measured properties. Note that the bias is represented by a ratio of logs, so that a ratio of 2 is actually quite larger. From Holt et al, $2002 \mathrm{c}$.

can also lead to the inclusion of parameters in the inversion model that are simply artifacts of the errors (Holt, 2000; Holt et al., 2002a), yet show realistic spatial statistics. Mcasurement errors 
also amplify uncertainty in experimental variograms caused by limited sampling and can preclude accurate identification of variogram-model parameters. The effects of observation and inversion model errors can be insidious, as hydraulic property estimates may appear reasonable and generate realistic looking spatial statistics which are, however, inaccurate and misleading. The parameters that describe the slope of the moisture-characteristic or unsaturated hydraulic conductivity curves are particularly sensitive to measurement errors and show the greatest bias (Holt, 2000; Holt et al., 2002a,b,c). However, it may be possible to accurately estimate spatial statistics of unsaturated scaling variables (saturated hydraulic conductivity, porosity, and parameters related to the air-entry pressure), especially if dircct measurements with nearly-linear or linear inversion models are used (e.g., Holt, 2000; Holt et al., 2002a).

We reluctantly conclude that robust estimation of unsaturated hydraulic properties for spatial variability studies is not possible with most current instruments and inversion models because multiple parameters are estimated using a single, nonlinear model. In addition, bias in spatial statistics of estimated hydraulic properties is extremely sensitive to different inversionmodel crrors, and it is not possible to identify a priori all types of inversion-model error that can affect a particular property estimation method. Therefore, error analyses cannot be used to uniquely identify all material types or conditions under which a particular instrument or inversion model will perform best or to temove bias caused by measurement errors.

Our results also suggest that property-measurcment errors can significantly impact stochastic-model flow and transport predictions and, by implication, the decisions based on these predictions. We observe order-of-magnitude errors in the results of analytical stochastic models for unsaturated flow and transport (Holt, 2000; Holt et al, 2002b,c). These errors originate in two ways: 1) critical predictive model assumptions may be violated, limiting the parameter space usable in the model and 2) predictive model results become biascd or systematically distorted. Predictive model assumptions are most violated under dry conditions. Errors are greatest (several orders of magnitude) for estimates of the velocity variance and velocity integral (spatial correlation) scale, which depend on variogram-model parameters, modest for estimates of the ensemble mean velocity (an order of magnitude; see Figure 4), and least for estimates of the macrodispcrsivity (under a factor of 2 ), due to compensating errors. If the input spatial statistics are inaccurate, then the magnitude of predictive model error changes with flow conditions. A "swect spot," where estimates of enscmble velocity parameters remain accurate regardless of moisture tension, can develop in that part of parameter space (some combination of parameters) where coincidentally all input spatial statistics are accurately estimated. A sweet spot is common in some part of a parameter space when measurements are affected by only observation errors, but its 'location' varies with the flow conditions. When inversion-model errors also affect measurements, it is less likely that the spatial statistics will be accurately estimated in an overlapping portion of parameter space, and there is no sweet spot. Similar behavior is likely when multiple properties are estimated using different methods, with varying measurement support, or at dissimilar time scales. 

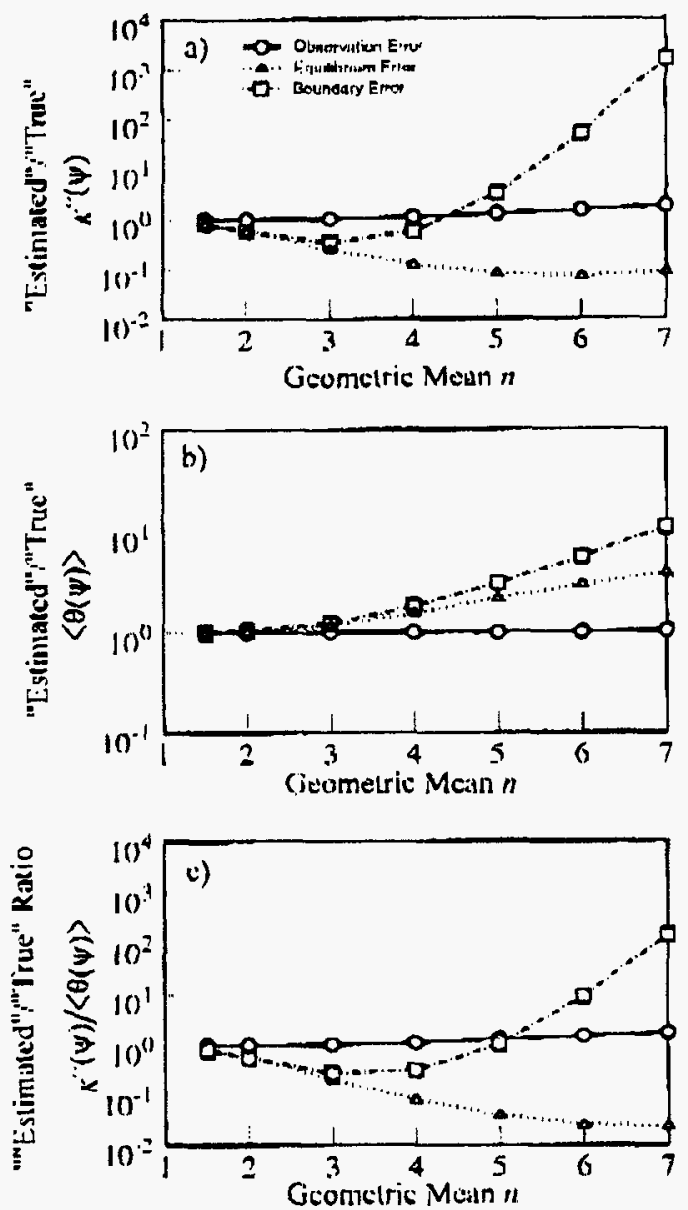

Figure 4. a) The geometric mean conductivity $\hat{K}^{c}(\psi)$, b) the mcan moisture content $\langle\hat{\theta}(\psi)\rangle$, and c) the ratio $\hat{K}^{g}(\psi) /\langle\hat{\theta}(\psi)\rangle$, for $\psi=-500 \mathrm{~cm}$, typical of scmi-arid vadose zone. The ratio is an estimator for vertical rate of movement of a contaminant in a gravity dominated vadose zone. When only observation errors are present all three variables are reasonably estimated, but when the model errors are also considered the estimates are inaccurate. In particular the ratio is consistently misestimated suggesting that,depending on the nature of the material, the rate of downward contaminant migration could be undcrestimated or over estimated by up to two orders of magnitude, From Holt et al, 2002c.

Wc conclude that, given the current mathematical modcls for unsaturated flow and the range of possible instruments, it is not possible to accurately cstimate the spatial statistics of parameters that describe the slope of the pressure-saturation and relative-permeability curves from either in situ or laboratory measurements unless certain conditions are met. Worse, the statistics have the appearance of being reasonable; we could find no reasonable diagnostic to detect the significant bias in the statistics. It is simply not possible to measure the spatial statistics of unsaturated properties using direct measurements because of the non-linear naturc of hydraulic measurements in porous media, and our inability to calibrate instruments. While 
individual components of an instrument (c.g., transducers) can be calibrated they still have noise. When this noise is propagated thorough the non-linear response of the instrument, and perhaps through model error as well, the calibrated noise leads to bias. For some instruments, mainly the more linear instruments and those with less model error, this bias is small enough to allow accurate estimation of spatial statistics. Fortunately we found that this is the case for some estimates of porosity and saturated permeability.

Bias in property measurements without calibration is a critical problem in groundwater hydrology with wide reaching implications. It potentially impairs our ability to directly characterize property heterogeneity and accuratcly predict flow and transport at contaminated sites. It may adversely affect the design, final cost, and effectiveness of remedial actions at contaminated sites. Given the scope of the DOE's environmental problem, additional rescarch related to property measurement bias and related spatial bias is imperative.

\section{RELEVANCE, IMPACT AND TECHNOLOGY TRANSFER}

a. How does this new scientific knowledge focus on critical DOE environmental management problems? Bias in property measurements without calibration is a critical but previously ignored problem with wide reaching implications. It potentially impairs our ability to directly characterize property hetcrogeneity and, at contaminated DOE sites, accurately predict flow and transport.

b. How will the new scientific knowledge that is generated by this project improve technologies and cleanup approaches to significantly reduce future costs, schedules, and risks and meet DOE compliance requirements?

While this project was not able to solve the bias problem, it brings it to the attention of the wider rescarch community. New approaches to the problem, some of them outlined below under Future Work, will have to be devcloped.

c. To what extent does the new scientific knowledge bridge the gap between broad fundamental research that has wide-ranging applications and the timeliness to meet needs-driven applied technology development?

Measurements for characterization are an intrinsic part of applied remediation tcchnology. Measurements are used to determine what is present, to provide data to predictive models used to test alternative remedial designs, and to monitor performance. That many of these measurements are not calibrated is largely ignored by the discipline. What this research shows is that even small unbiased errors can cause significant bias when filtered through a non-linear measurement, possibly leading to inaccuratc characterizations, ineffective designs, and even faulty monitoring.

d. What is the project's impact on indlviduals, laboratories, departments, and institutions? Will results be used? If so, how will they be used, by whom, and when?

The immediate impact of these findings is on those for whom vadose zone processes are most important, such as the Hanford Reservation, INEEL, Los Alamos, and Sandia. INEEL and Sandia are following up this work. While the particular system we examined concemed vadose zone hydraulic properties it is also reasonable to expect that similar 
findings could arise for other flow or reactive chemical settings. Sandia is examining this issue for aquifer well tests.

e. Are larger scale trials warranted? What difference has the project made? Now that the project is complete, what new capacity, equipment, or expertise has been developed?

The conclusions are biased on Monte Carlo simulation, since that is the only way to make enough "measurcments" to get a clear picture. Other approaches to the bias issue should be attempted, including reanalysis of existing and new data sets. Other approaches to estimating spatial statistics should be developed, and some of these are outlined in the Future Work section.

f. How have the scientific capabilities of collaborating scientists been improved?

This work calls into question the use of large punctual data sets for the parameterization of stochastic models. This comes just when we thought that, at the very least, we can rcly on this kind of data to test and condition other estimation approaches. As a result, efforts can now be redirected toward establishing the value of these large sets by a priori cxamining their propensity for spatial bias, and by more formally incorporating feasible calibration protocols into experimental design.

g. How has this research advanced our understanding in the area?

We now know that the widespread use of uncalibrated measurements in hydrology can have significant negative consequences, suggesting that the classic issue of instrument calibration needs to be revisited in this hydrologic context.

h. What additional scientific or other hurdles must be overcome before the results of this project can be successfully applied to DOE Environmental Management problems?

The results can be applied now, by considering these issues when developing estimates of spatial statistics.

i. Have any other government agencies or private enterprises expressed interest in the project? Please provide contact information.

No.

\section{PROJECT PRODUCTIVITY}

The project requested and received a one ycar no-cost extension due to the change in both the focus and work plan, as described above in the section on objectives. Despite testing several design alternatives no new instrument was produced because the project discovered that direct ficld measurements could not be uscd to characterizc the spatial statistics of unsaturated hydraulic properties. Instcad a computer based design tool, employing Monte Carlo simulation, was developed and used to investigate how measurement noise filtered through a non-linear instrument to produce unacceptable bias in estimated statistics. This tool is now available to interrogate other instrument designs, for mcasurements in the vadose or saturated zones

\section{PERSONAL SUPPORTED}

This project supported the PI's and two graduate students:

John L. Wilson, Professor and PI 
Robert J. Glass, Sandia Scientist, co-PI, and adjunct Professor

Robert M. Holt, graduate student and $\mathrm{PhD}$ candidate

Eric Aronson, graduate student and MS candidate

Zak Brown, graduate student and MS candidate

\section{PUBLICATIONS}

\section{Peer-Reviewed Joumals}

Holt, R. M., J. L. Wilson, and R. J. Glass, 2002a, "Spatial Bias in Ficld-Estimated Unsaturated Hydraulic Propertics," in press, Water Resources Research.

Holt, R. M., J. L. Wilson, and R. J. Glass, 2002b, "Error in Unsaturated Stochastic-Models Paramcterized with Field Data," accepted by Water Resources Research.

Holt, R. M., R. J. Glass, and J. L. Wilson, 2002c, "Spatial Bias in Laboratory-Estimated Unsaturated Hydraulic Propertics," in review, submitted to Water Resources Research.

Holt, R. M, 2002 "Approximate Solution of Steady Unsaturated Flow Equations using a Piecewise Continuous Hydraulic Conductivity Function," in preparation for submission to Water Resources Research.

\section{Conference Papers}

Holt, R. M., 2000, "Can we Parameterize Stochastic Models of Flow and Transport in the Vadose Zone," Abstract, Twelfth TIE Workshop Book, U.S. Department of Energy, p. 165.

Holt, R. M., J. L. Wilson, and R. J. Glass, 1998, "Estimating Variogram-Model Parameters for Hydraulic Properties in the Presence of Measurcment Error: Example from the Tension Infiltrometcr," Abstract, EOS Transactions, American Geophysical Union, Vol. 79, No. 45, p. F267

Holt, R. M., J. L. Wilson, and R. J. Glass, 1999, "Spatial Bias in Unsaturated Hydraulic Properties due to Laboratory Error," Abstract, EOS Transactions, American Geophysical Union, Vol. 80 , No. 46, pp. F389-390

Hoit, R. M., J. L. Wilson, and R. J. Glass, 2000, "Spatial Bias in Unsaturated Hydraulic Property Estimates: Origin, Impact, and Relevance," U. S. Department of Encrgy, Environmental Management Science Program, Annual Meeting, Atlanta, GA, April, 2000. See poster at http://www.osti.gov/em52/1998posters/id55109.pdf

Holt, R. M., J. L. Wilson, and R. J. Glass, 2000, "Error in Unsaturated Stochastic-Models Parameterized with Field Data," Abstract, EOS Transactions, Amcrican Geophysical Union, Vol. 81 , No. 48 , p. F408. 
Wilson, J.L., 1998, "New Permeameters for the In situ Characterization of Unsaturated Permeability," , U. S. Department of Energy, Environmental Management Science Program, 1998 Project Summaries, http://cmsp.em.doe.gov/pdfs/emsp.pdf, 296-297.

\section{Theses and Dissertations}

Aronson, Eric, 1999, "Modeling investigations on gas permeametcrs: spatial weighting functions and layered systems ," unpublished M.S. Independent Study, Dept. of Earth \& Environmental Science, N. M. Institute of Mining and Technology, Socorro, N.M., 91 pp.

Holt, R. M., 2000, "Spatial bias in unsaturated hydraulic property estimates: origin, impact, and relevance," unpublished Ph.D. Thesis, Dept. of Earth \& Environmental Science, N. M. Institutc of Mining and Technology, Socorro, N.M., $160 \mathrm{pp}$.

\section{INTERACTIONS}

Presentations were made at six meetings. Published abstracts for some of these presentations are cited abovc. These meetings are:

- National Workshop, Environmental Management Science Program, U. S. Department of Energy, Chicago, IL, July, 1998.

- Fall Annual Meeting American Geophysical Union, San Francisco, CA, December, 1998.

- Fall Annual Meeting American Geophysical Union, San Francisco, CA, December, 1999.

- Vadose Zone Characterization Meeting, Pacific Northwest National Laboratory, Richland, WA, January, 2000.

- Fall Annual Meeting American Geophysical Union, San Francisco, CA, December, 2000.

- National Workshop, Environmental Management Science Program, U. S. Department of Encrgy, Atlanta, GA, April, 2000.

Following the PNNL meeting and later the EMSP meeting in 2000, we established a closer relationship with the Subsurface Science Laboratory at INEEL. This resulted in scveral collaborations with Earl Matson, Buck Sisson, and Annette Schaffer. Also following the PNNL meeting we were in contact with the Hanford Tank Focus Arca about performing a similar tcst at the Hanford Reservation. Following graduation, at the end of the project, grad student Robert $M$. Holt took a faculty position with the University of Mississippi at Oxford. INEEL then supported him to spend the summer of 2001 at the lab in order to follow up on the results of this work, in particular investigating methods to overcome spatial bias in hydraulic property measurements. He will continue this activity at INEEL in the summer of 2002 . He recently submitted a proposal for a related field experiment with INEEL's Sisson and Schaffer. He has also been awarded a contract to collaborate with Mr. Randy Roberts at Sandia National Laboratories to investigate the impact of inversion modcl errors on transmissivity estimates from well tests.

John L. Wilson and Robert J. Glass have both served on several committecs on for the DOE complex-wide Vadose Zone Science and Technology Roadmap: characterization, and 
modeling of subsurface contaminant fate and transport. Wilson is still a member of the Executive Committee and Chaired the Committee on Modeling.

\section{TRANSITIONS}

INEEL (names above) is concerned with the movement of water and chemicals through the deep vadose zones of the arid and semi-arid west, and how to characterized heterogeneity and its influence on these processes. Their immediate application of this work is to the sediments at the site itself, where sediment layers overlic basalts, but they also recognize other applications to Hanford, Sandia and other DOE facilities. They are attempting to address the issues raised by the results of this project by developing alternative approaches, not involving direct measurcments, some of which are discussed below under future work.

\section{PATENTS}

Although this project was originally aimed at the development of new instruments, the spatial bias problem led us in other directions. No new instruments worthy of patent protection were developed.

\section{FUTURE WORK}

The primary purpose for site characterization activities is to provide data for conceptual and predictive subsurface models, including probabilistic models of contaminant transport for decision making. Although many techniques exist for incorporating site-specific observations of hydraulic parameter heterogeneity into a probabilistic risk framework for decision analysis, they cannot be reliably applied without first quantifying the unccrtainty in hydraulic parameter data. If the character and extent of spatial bias is unknown, parameter estimates may be overvalued, rcsulting in costly site-characterization and poor remedial decisions. Until now, the effects of spatial bias due to measurement errors werc ignored. While results produced by this project represcnt an important first step it only examines a limited set of measurements. We must take a step back and evaluate the impact of spatial bias on nearly all of our property-estimation methods and the models that require these hydraulic properties. Some of the work that should be done is described below. While this listing is by no means comprchensive, it does provide initial direction for future research activities.

Evaluate Other Property-Estimation Methods. Although we have considered several of the standard methods for estimating unsaturated hydraulic properties, a number of current techniques remain unevaluated, including centrifugal methods for estimating moisture characteristic curves (used by INEEL, LANL, PNNL, and Hanford), numerical inversion of tension infiltrometer data, and pedotransfer functions. The impact of measurement errors on the spatial statistics of properties estimated with a wider variety of current methods should be determined.

Consider Spatial Bias in the Design of New and Emerging Technologies. New techniques for estimating properties, including geophysically based methods, should be developed with consideration of measurement-error-induced spatial bias. A systematic 
design approach could be employed, where design decisions, component selection, and implementation methods are chosen to minimize spatial bias, ensuring maximum data value.

Consider the Impact of Measurement Error on Data Worth. Although a large body of research has focuscd on evaluations of data worth, with the goal of optimizing data sampling locations, the impact of realistic measurcment errors have been neglected. Most treatments of data worth assume that hydraulic parameter measurement errors are unbiascd and that parameter uncertainty only arises from incompletc sampling and nonideal sample locations. However, these assumptions are generally invalid because measurement errors can be spatially biased, and this bias amplifies sampling uncertainty. The impact of measurement-error-induced spatial bias should be considered when evaluating site-specific data worth.

Evaluate Non-Parameteric Geostatistics. Indicator geostatistics are a very powerful non-parameteric tool for characterizing spatial variability. Indicator functions transform property value into a binary random variable, either 0 or 1 , depending upon whether or not the property exceeds a threshold value. For non-categorical random spacc functions, threshold values are typically selected to represent quantiles (c.g., the median).

Variograms of indicator functions are extremely robust, because their estimation does not depend on property values. Because indicator-variogram models contain only two unknowns (corrclation length and nugget variance), they can be more reliably fit to indicator variograms. Indicator variograms may reveal the pattern of spatial variation for unsaturated hydraulic properties that cannot be cvaluated using classical geostatistical techniques. The impact of measurement-error-induced spatial bias on indicator statistics should be evaluated.

Evaluate the Impact of Spatial Bias on Conditional Stochastic Models. Most practical applications of stochastic models involve conditioning on site-specific data and the use of boundary conditions and parameter ficlds that producc non-stationary flow conditions. When used in a decision-making process these models offer an advantage, because solutions are constrained by site-specific data and estimated second and higher moments are smaller, implying lower uncertainty and increased confidence in the results. When the hydraulic property data have been cstimated in the presence of observation or inversion-model errors, however, the increased confidence may not be warranted, as bias in the results erodes the advantages of conditional approaches. The impact of measurement-error-induced spatial bias on conditional stochastic models needs to be evaluated.

Finally, the Monte Carlo simulation design tool, used here to investigate, e.g., the tension infiltrometer and various lab methods, could be formulated into a tool for the evaluation of a much widcr suite of measurement types, for both the saturated and unsaturated zones. A study using this approach to investigate saturated zone well tests has already been funded in collaboration with Sandia National Laboratories. In such an approach to new measurement types all of the topics listed just above remain relevant. 


\section{REFERENCES CITED}

Holt, R. M., J. L. Wilson, and R. J. Glass, 2002a, "Spatial Bias in Field-Estimated Unsaturated Hydraulic Properties," in press, Water Resources Research.

Holt, R. M., J. L. Wilson, and R. J. Glass, 2002b, "Etror in Unsaturated Stochastic-Models Parametcrized with Field Data," accepted by Water Resources Research.

Holt, R. M., R. J. Glass, and J. L. Wilson, 2002c, "Spatial Bias in Laboratory-Estimated Unsaturated Hydraulic Propertics," in review, submitted to Water Resources Research.

Robin, M.J.L., A.L. Gutjahr, E.A. Sudicky, and J.L. Wilson, 1993, "Cross-Correlated Random Field Gencration with the Direct Fourier Transform Method," Water Resources Research, 29(7), 2385-2397.

van Genuchten, M. Th., 1980, "A closed-form equation for predicting the hydraulic conductivity of unsaturated soils," Soil Science Society of America Journal, 44, p. 892-898.

Wilson, J.L., 1998, "New Permeameters for the In situ Characterization of Unsaturated Permeability," ,"U. S. Department of Energy, Environmental Managcment Science Program, 1998 Project Summarics, http://emsp.em.doe.gov/pdfs/entsp.pdf, 296-297. 